\title{
JARISCH-HERXHEIMER REACTION FOLLOWING PENICILLIN TREATMENT OF EARLY CONGENITAL SYPHILIS*
}

\author{
BY \\ A. HOLZEL \\ Department of Child Health, University of Manchester
}

\begin{abstract}
With improved antenatal care, congenital syphilis in Great Britain has come to be regarded as one of the rare diseases of infancy and childhood. However, as an aftermath of the second world war there was a marked increase in the incidence of early acquired syphilis which reached its peak in the year 1946. Not unexpectedly, it resulted in a steep rise in the number of congenital syphilis cases in 1948 and 1949 , followed by a gradual fall in the ensuing years to a low level in 1952 (Morton, 1954).
\end{abstract}

Earlier communications on penicillin treatment of congenital syphilis, particularly from the U.S.A., were almost unanimous in their opinion that it was the best single therapeutic agent available. Platou (1949), reviewing his own results in 180 patients as well as those recorded by others, supported this view emphatically. He claimed that no serious untoward effect had occurred; although 39 per cent.of the children in his series had transient febrile reactions in the course of the first 36 hours after the onset of treatment, in none were these severe enough to warrant cessation of treatment. Heyman and Yampolski (1946) had noticed febrile reactions in twelve out of 22 children. They occurred within 24 hours after the beginning of penicillin therapy and the fever occasionally reached $104^{\circ} \mathrm{F}$. but treatment was continued without interruption in every case. Febrile episodes were recorded by Farmer (1948) in over 40 per cent. of adult patients with early syphilis; Scott, Maxwell, and Skinner (1949) observed two fatal Jarisch-Herxheimer phenomena in adult patients with late syphilis. Pardo and Tucker (1949) found a rise in temperature following the beginning of treatment in 48.5 per cent. of their cases suffering from congenital syphilis. Putkonen (1950) found it in fifteen out of sixteen treated children.

Ehrengut (1950) reported a fatal Jarisch-Herxheimer reaction in a 3-months-old baby after the first penicillin injection. Stenger (1950) thought the Jarisch-Herxheimer reaction a possible contributory fatal factor in three infants. Similarly Meyer and Herkenhof (1951) suspected an untoward penicillin effect as an additional cause in four fatal cases.

\footnotetext{
* Received for publication February 1, 1956.
}

Debré, Lami, Mozziconacci, and Labesse (1951) had no doubt that in four infants the Jarisch-Herxheimer phenomenon had hastened the lethal outcome. Three of the babies died during the first 24 hours after the start of treatment. Seelig and Sudhoff (1952) regard the Jarisch-Herxheimer as a minor therapeutic trauma which, however, led to the death of three seriously affected babies. Küster and Bechmann (1952) attribute fatalities to it in at least three cases of early congenital syphilis. Oehme (1951), on the contrary, in his report on 118 infants and children, thought the dangers of a JarischHerxheimer reaction widely overrated.

During the 5-year period, January, 1948-December, 1952, eighty cases of congenital syphilis in infants and children were treated at the three Manchester Children's Hospitals (Royal Manchester Children's Hospital, Booth Hall Children's Hospital, and Duchess of York Hospital for Babies). Of these 45 were under one year of age and presented the well-known manifestations of early congenital syphilis. In all cases of this group, on which the following report is based, penicillin was the sole and exclusive form of therapy. For the older children with late signs it was employed in conjunction with other more conventional methods of treatment, such as the arsenicals, bismuth and artificial fever.

The mortality rate of the eighty patients is shown in Table I. They are divided into three categories according to their ages. Only the first two groups will be considered in detail as they represent the infants with early congenital syphilis who were treated with penicillin only.

TABLE I

MORTALITY IN EIGHTY CASES OF CONGENITAL SYPHILIS TREATED WITH PENICILLIN

\begin{tabular}{c|c|c|c|c}
\hline Age & $\begin{array}{c}\text { Number } \\
\text { of Cases }\end{array}$ & Recovered & Died & $\begin{array}{c}\text { Mortality Rate } \\
\text { (per cent.) }\end{array}$ \\
\hline $0-3 \mathrm{mths}$ & 32 & 18 & 14 & $43 \cdot 75$ \\
\hline $3-12 \mathrm{mths}$ & 13 & 8 & 5 & $38 \cdot 46$ \\
\hline $1-14 \mathrm{yrs}$ & 35 & 35 & 0 & 0 \\
\hline Total.. & 80 & 61 & 19 & $23 \cdot 75$ \\
\hline
\end{tabular}


It is evident that the highest mortality rate is encountered in the youngest age group ( $0-3$ months). In itself this is not surprising, since the earlier the signs of syphilis appear the more severe and widespread is the infection likely to be. The large number of deaths that occurred under penicillin treatment was very disappointing. A careful scrutiny of the records of the nineteen fatal cases strongly suggests that a reaction of the Jarisch-Herxheimer type to penicillin was a contributory fatal factor in ten infants.

These reactions conformed to two definite patterns which, though similar in their clinical manifestations, differed in their course.

The following case history illustrates the first type:

Case 1.-A 3-months-old infant was admitted to hospital with typical skin manifestations, distended abdomen, large liver and spleen, free fluid in the peritonal cavity, and oedema of the lower limbs. The baby's delivery had been premature (birth weight 4 lb.). The Wassermann reaction (WR) of both parents was positive. There were two other children who seemed well. This infant had had blood tests performed on two occasions with negative results and no clinical signs until the week before admission. At a third test the Wassermann reaction was strongly positive.

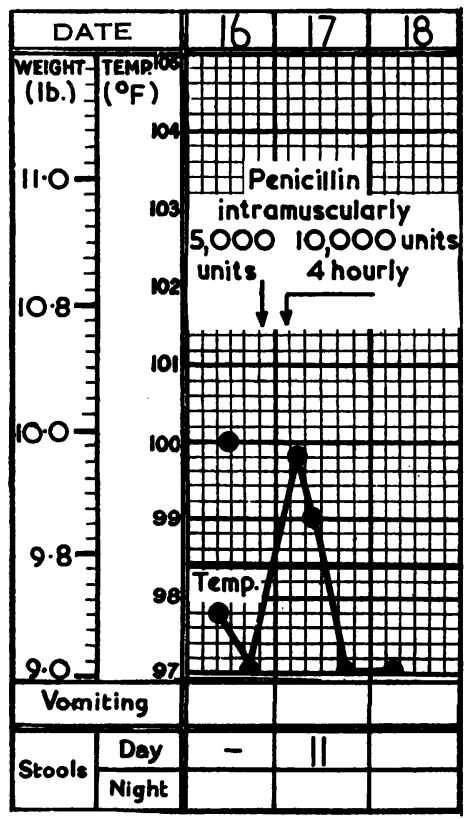

FIG. 1.- Sudden rise of temperature after first penicillin injection, followed by a fatal syncopal attack in the course of 24 hours (Case 1).
Penicillin treatment was started on the day of admission; the first dose consisted of 5,000 units intramuscularly and was followed by 10,000 units every 4 hours. Within 12 hours after the first injection the baby became distressed and showed laboured respirations, the oedema as well as the abdominal distension increased, the pulse became feeble, and the baby vomited, collapsed, and died (Fig. 1).

In three out of the ten cases regarded as showing a Jarisch-Herxheimer reaction, death occurred within the first 24 hours, presenting the same frightening sequence of events; a sudden rise in temperature, abdominal distension, extreme respiratory distress, two or three loose motions, and a large vomit preceding a final syncopal attack.

The second type of reaction in the other seven cases, though somewhat diverse in the severity of the individual symptoms, retrospectively conformed unmistakably to a particular syndrome. Pyrexia again followed within 4 to 12 hours after the first penicillin injection; it receded somewhat in the course of 24 hours or so, but weight loss continued. The infant's general condition deteriorated but not as dramatically as in the first group, abdominal distension became evident, pallor was marked; and oedema occasionally appeared as well as an exacerbation of an already present jaundice or its development. Stools were loose, but not frequent, and there was occasional vomiting. The rash and nasal discharge, however, disappeared. Towards the end of the first week after beginning treatment, death occurred with the picture of a sudden peripheral circulatory failure.

Thus we have the picture of an infant whose defence mechanism was already heavily taxed by a severe infection and was unable to withstand the additional stress of the Herxheimer reaction and, although not breaking down immediately, nevertheless succumbed shortly after. The following case histories demonstrate such a pattern of events:

Case 2.-A 4-months-old female infant (birth weight $7 \mathrm{lb} .9 \mathrm{oz}$., normal delivery at full-term) weighed $12 \mathrm{lb}$. $7 \mathrm{oz}$. on admission. At the age of $2 \frac{1}{2}$ months she was first noticed to have nasal obstruction and later developed a bloodstained discharge; 2 weeks before admission a reddish-brown rash appeared on her limbs and buttocks.

Family History.-Both parents seemed well and healthy and unaware of any infection. Subsequently it was found that both had strongly positive Wassermann reactions.

Examination.-The infant appeared well-nourished and did not look very ill. There was a thin haemorrhagic nasal discharge, rhagades round mouth and nose, a typical macular rash, syphilitic psoriasis of palms and soles, oedema of the dorsum of the hands and feet, and enlarged liver and spleen. The Wassermann reaction was strongly positive. Mantoux test $(1: 1000)$ negative. 


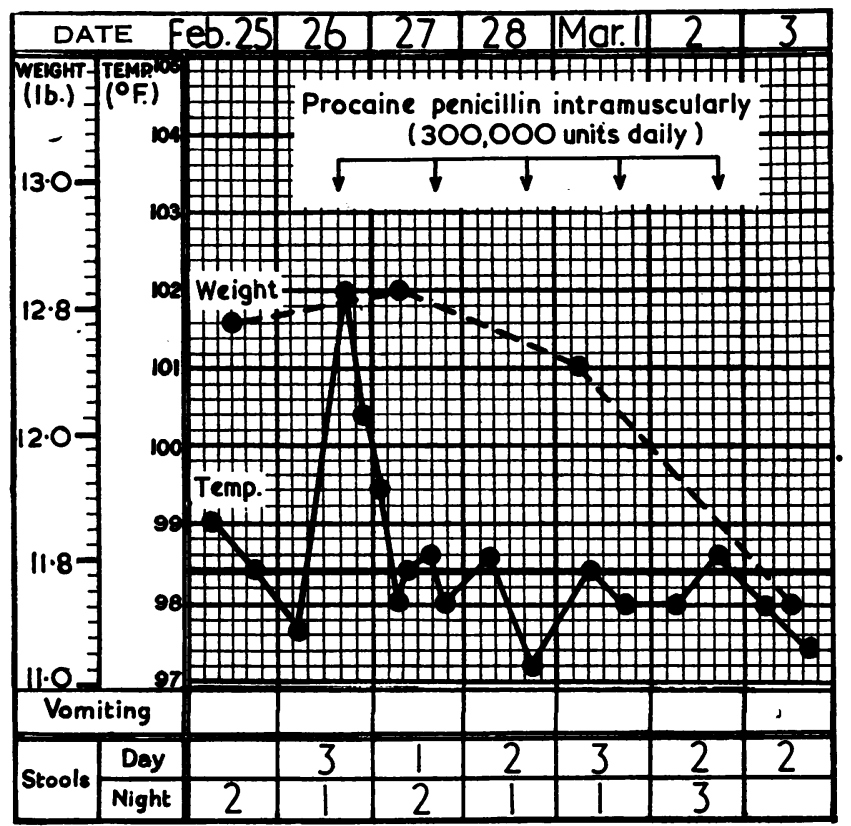

Fig. 2.-Pyrexia of $102^{\circ} \mathrm{F}$. after first dose of penicillin and subsequent fall in weight. Syncope on 6th day after start of treatment (Case 2).

Progress.-The child was started on daily injections of 300,000 units procaine penicillin; 12 hours after the first injection the temperature, which had been normal, rose to $102^{\circ} \mathrm{F}$., but returned to normal within a further 12 hours. During the following days the rash faded and the nose ceased to discharge but the oedema became more marked and the stools more frequent and loose. Her weight fell and, though she appeared unwell, at no time did she seem critically ill. On the sixth day she died suddenly, having vomited immediately before death (Fig. 2).

Post-mortem Examination.-There was some excess of straw-coloured fluid with fibrinous exudate in the peritoneal cavity. The spleen was enlarged, dark red, and there was fibrinous perisplenitis. The enlarged liver was, on section, of a rather translucent greyish-brown appearance with many bright yellow areas suggestive of massive necrosis. Histological study confirmed this finding. There were no spirochaetes to be seen.

Case 3. - The first of binovular male twins, born at full term (birth weight $8 \mathrm{lb}$.) was snuffly from the first few days of life and had blood-stained nasal discharge. On the 25th day a coppery rash appeared on his face and later spread to his arms, legs, and buttocks. At 3 weeks of age he had started with vomiting, which persisted. Although he had the clinical signs of an infection he was regarded as the twin who thrived the better.

Family History.-The father was alive and well, and his Wassermann reaction was later ascertained to be negative. The mother's Wassermann reaction was positive but she was unaware of any infection. An older child who had a different father seemed healthy but his Wassermann reaction was strongly positive.

Examination. - The baby appeared wellnourished but had a blood-stained nasal discharge. A brownish-red macular rash was present on the face and extremities, and rhagades on the lower lip. The abdomen was distended, the liver edge four fingerbreadths below the costal margin, and the spleen enlarged down to the umbilicus.

Progress. - Treatment with 300,000 units procaine penicillin was commenced on the first day in hospital. During the night the baby, who had been afebrile, became pyrexial; on the following day the stools were loose, frequent, and yellowish in colour, and 3 days later he became jaundiced. Because of the deterioration in his condition and his severe anaemia (Haemoglobin 38 per cent., red blood corpuscles $1,800,000$ ) he was given a blood transfusion and the penicillin treatment was stopped. There followed some improvement in the child's general state, but the jaundice continued to become more intense and he died suddenly on the 8th day after beginning treatment (Fig. 3, overleaf).

Post-mortem Examination.-The most striking changes were again found in the liver, which appeared greasy, yellow, with smooth surface. The kidneys were extremely pale. The vessels of the brain were engorged, and its substance oedematous. All organs were bile-stained.

Extensive liver necrosis was found on histological examination.

Case 4.-The first child of apparently healthy parents (delivery normal at full term; birth weight $6 \frac{1}{2} \mathrm{lb}$.) weighed $15 \mathrm{lb} .3 \mathrm{oz}$. at the age of 7 months when admitted with vomiting and weaning difficulties.

Examination.-He was a fat lively baby who had made no attempt at sitting up or holding up his head. The anterior and posterior fontanelles were wide open and soft areas could be felt in the parietal regions of the skull. The liver was enlarged, the edge being about three fingers below the costal margin. Radiological examination of skull and long bones was strongly suggestive of congenital syphilis. Wassermann reaction $1: 8$ positive.

Therapy. $-50,000$ units penicillin every 3 hours was given by intramuscular injection; 5 hours after the first injection the temperature, which had been normal, rose to $100^{\circ} \mathrm{F}$. Coarse nystagmus appeared but there were no other manifestations which indicated any worsening in the baby's condition. However, after one day's interval, the pyrexia returned and the most assiduous search did not reveal any additional infection. On the 5th day after the start of therapy hyperpyrexia $\left(106 \cdot 4^{\circ} \mathrm{F}\right.$. developed). Penicillin treatment was discontinued but the baby died within minutes, though a few hours before there was nothing to foreshadow an imminent crisis (Fig. 4, overleaf).

Post-mortem Examination.-Once more macroscopically and microscopically extensive necrosis of the liver, 

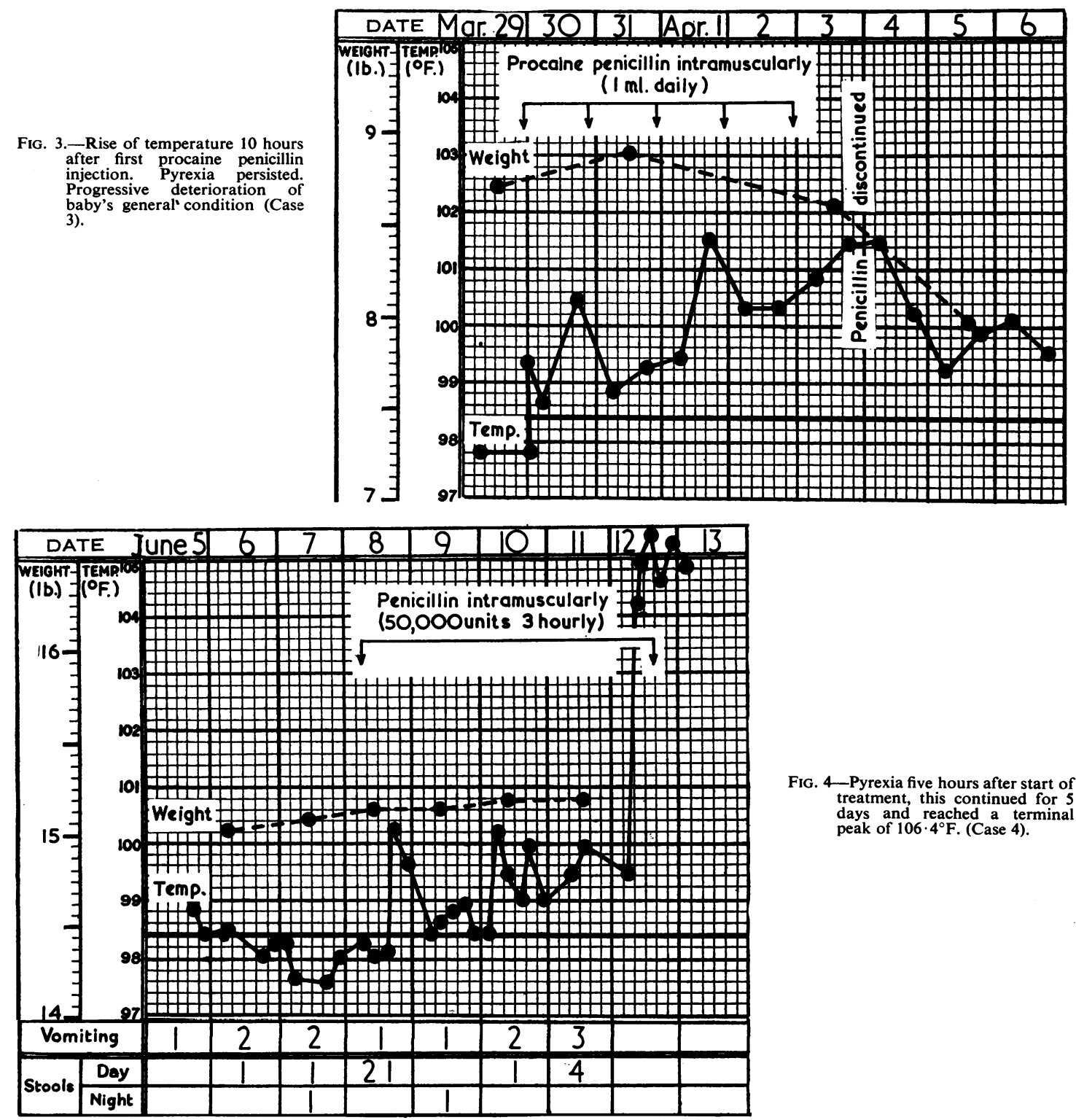

Fig. 4-Pyrexia five hours after start of treatment, this continued for 5 days and reached a terminal peak of $106 \cdot 4^{\circ} \mathrm{F}$. (Case 4 ).

and engorgement and oedema of the brain were the only striking findings.

A review of the clinical manifestations as noted on admission in ten cases of fatal Jarisch-Herxheimer reaction shows that the relatively early onset of the disease was common to all of them. All the infants, with the exception of one who was 7 months old, were under 6 months of age (Table II, opposite).

A second common feature was hepatomegaly. This is the more likely the earlier and more wide- spread the syphilitic process. Somewhat less frequent was splenomegaly. Osseous lesions were not more severe in these ten cases than in those who recovered. However, it emerged that the skull bones, particularly in the parietal and frontal areas, were often involved. As a rule the syphilitic osteitis in long bones and skull was of a corresponding degree, but the cranial lesions were more marked in some.

Thymol turbidity tests were carried out in a number of infants in an attempt to assess the derangement of the liver function. In all infants 
TABLE II

CLINICAL MANIFESTATIONS OF CONGENITAL SYPHILIS IN TEN CASES WHO DEVELOPED A FATAL HERXHEIMER REACTION DURING PENICILLIN THERAPY

\begin{tabular}{|c|c|c|c|c|c|c|c|c|c|c|}
\hline \multicolumn{4}{|c|}{ Age } & \multirow{2}{*}{$\frac{\text { Rash }}{+}$} & \multirow{2}{*}{$\frac{\text { Snuffles }}{-}$} & \multirow{2}{*}{$\frac{\text { Pyrexia }}{-}$} & \multirow{2}{*}{$\frac{\text { Hepatomegaly }}{+}$} & \multirow{2}{*}{$\frac{\text { Splenomegaly }}{+t}$} & \multirow{2}{*}{$\begin{array}{c}\begin{array}{c}\text { Bone } \\
\text { Involvement }\end{array} \\
-\end{array}$} & \multirow{2}{*}{$\frac{\text { Jaundice }}{-}$} \\
\hline 3 days & $\cdots$ & $\cdots$ & . & & & & & & & \\
\hline 4 wks & . & $\ldots$ & . & + & + & + & ++ & ++ & - & - \\
\hline $3 \mathrm{mths}$ & . & . & . & - & - & + & ++ & ++ & + & - \\
\hline $1 \mathrm{mth}$ & $\ldots$ & . & . & - & + & - & + & + & - & - \\
\hline 3 mths & . & .. & .. & + & - & - & ++ & + & + & - \\
\hline $5 \mathrm{mths}$ & . & . & . & + & + & + & ++ & \pm & + & - \\
\hline $4 \mathrm{mths}$ & . & . & $\ldots$ & + & + & - & + & + & + & - \\
\hline $10 \mathrm{wks}$ & . & . & .. & - & - & - & + & + & ++ & + \\
\hline $4 \mathrm{mths}$ & . & . & . & - & + & + & + & + & + & - \\
\hline $7 \mathrm{mths}$ & .. & . & . & - & - & - & + & - & $+t$ & - \\
\hline
\end{tabular}

with florid syphilis the result of the tests was grossly abnormal but there was no direct correlation between it and the appearance of a Jarisch-Herxheimer reaction (Table III). Lower values were encountered in older children, often without evidence of liver enlargement. Generally, with clinical, serological, and radiological improvement, the thymol turbidity test returned to normal. Progressive deterioration was accompanied by a rise in thymol turbidy.

TABLE III

THY்MOL TURBIDITY TESTS IN SIXTEEN CASES OF CONGENITAL SYPHILIS

\begin{tabular}{|c|c|c|c|c|c|c|c|}
\hline \multicolumn{6}{|c|}{ Age } & \multirow{2}{*}{$\begin{array}{c}\begin{array}{c}\text { Thymol } \\
\text { Turbidity } \\
\text { Test }\end{array} \\
7 \\
12 \\
7 \\
15 \\
11 \\
12 \\
14 \\
12 \\
9 \\
8 \\
8\end{array}$} & \multirow{2}{*}{ 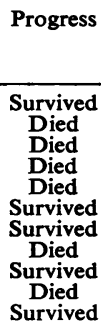 } \\
\hline $\begin{array}{c}2 \text { mths } \\
1 \text { mth } \\
3 \text { mths } \\
11 \text { wks } \\
10 \text { wks } \\
3 \text { mths } \\
4 \text { mths } \\
5 \text { wks } \\
6 \text { wks } \\
7 \text { mths } \\
2 \text { mths }\end{array}$ & $\begin{array}{l}. \\
\because \\
\because \\
\cdots \\
\cdots \\
\cdots \\
\cdots \\
\cdots\end{array}$ & $\begin{array}{l}\cdots \\
\cdots \\
\cdots \\
\cdots \\
\cdots \\
\cdots \\
\cdots \\
\cdots\end{array}$ & $\begin{array}{l}\ldots \\
\cdots \\
\cdots \\
\cdots \\
\ldots \\
\cdots \\
\cdots \\
\cdots\end{array}$ & $\begin{array}{l}\because \\
\because \\
\because \\
\because \\
\because \\
\because \\
\because \\
\because\end{array}$ & $\begin{array}{l}\ldots \\
\ldots \\
\cdots \\
\cdots \\
\cdots \\
\cdots \\
\cdots \\
\cdots\end{array}$ & & \\
\hline $\begin{array}{l}2 \frac{1}{2} \text { yrs } \\
3 \text { yrs } \\
7 \text { yrs } \\
10 \text { yrs } \\
8 \text { yrs }\end{array}$ & $\begin{array}{l}. \\
\cdots \\
\cdots\end{array}$ & $\begin{array}{l}\cdots \\
\cdots \\
\cdots\end{array}$ & $\begin{array}{l}\ldots \\
\ldots \\
\ldots \\
\ldots\end{array}$ & $\begin{array}{l}. \\
\because \\
\therefore\end{array}$ & $\begin{array}{l}\ldots \\
\cdots \\
\ldots\end{array}$ & $\begin{array}{l}8 \\
8 \\
5 \\
0 \cdot 5 \\
3\end{array}$ & $\begin{array}{l}\text { Survived } \\
\text { Survived } \\
\text { Survived } \\
\text { Survived } \\
\text { Survived }\end{array}$ \\
\hline
\end{tabular}

\section{Discussion}

Among the factors conducive to a grave JarischHerxheimer response in the penicillin treatment of congenital syphilis, age is one of the most important. As already shown, nine out of ten patients in whom it is assumed that the reaction may have had lethal significance were under 6 months of age and the tenth only one month older. No doubt the intensity of the syphilitic process in the infants with an early onset of the disease is very much greater and is more likely to extend to the majority of parenchymatous organs. Of these the liver seems to be most heavily involved and the additional burden of the JarischHerxheimer phenomenon may well have led to complete failure of its function. Hepatic cell injury may in some cases be so widespread that there is hardly any normal tissue left (Fig. 5, overleaf).

Hepatomegaly and jaundice clinically and elevated thymol turbidity biochemically are alarm signals. High penicillin dosage as a precipitating agent had been disregarded after the observation of Farmer (1948) in the treatment of early adult syphilis that the phenomenon could be noticed after doses as low as 10 units penicillin per $\mathrm{kg}$. bodyweight, and that the incidence remained constant at about 40-50 per cent. irrespective of the quantity of penicillin injected. One was therefore tempted to consider it as an "all or none" type of response. The ten cases here reported had each been treated according to a different schedule, ranging from 1,000 to 200,000 units per lb. bodyweight, and so seem to support the "all or none" conception.

Heyman, Sheldon, and Evans (1952) studied the histological changes during the Jarisch-Herxheimer reaction in patients suffering from syphilitic skin lesions as well as in experimental animals. They were of a decidedly inflammatory nature. There was opening up of existing blood vessels and the appearance of large numbers of new small blood vessels engorged with neutrophil cells, oedema of the interstitial tissues, and diapedesis of polymorphonuclear cells which were subsequently replaced by mononuclear cells-the whole process dying down within approximately 72 hours. As the cause of the inflammatory activity they accepted hypersensitivity to the breakdown products of the spirochaetes similar to 


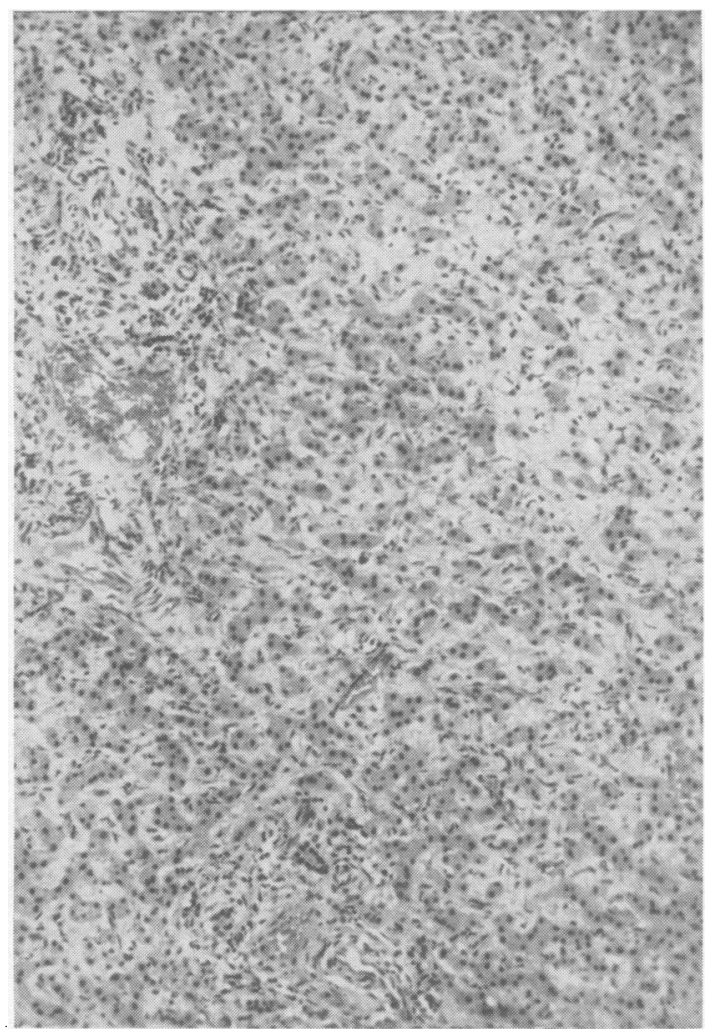

FIG. 5.-Extensive destruction of liver tissue in a case with JarischHerxheimer reaction.

the response to injected tuberculin in tuberculous patients or tuberculous experimental animals. If this view is correct (and there is at present no valid argument against it), then the reaction may vary quantitatively to some extent with the dosage. Antihistamines, cortisone, and ACTH failed to prevent the phenomenon.

There is some clinical evidence to support this opinion. Küster and Bechmann (1952) claim to have practically eliminated serious Jarisch-Herxheimer reactions by employing delayed-action penicillin, injecting 5,000 units divided in two daily doses for the first 3 days-then rapidly increasing it.

Seelemann and Kornatz-Stegmann (1952) found that a penicillin blood level of 0.09 units per ml. was already spirochaetocidal and that with a single dose of 500 units the critical threshold was easily transgressed. This observation also may explain the rapid disappearance of spirochaetes from the various organs. These authors recommend 3-hourly intramuscular administration of 100 units penicillin for 24 hours followed by 500 units 3-hourly for a further day, then 1,000 units at the same intervals for an additional day. 300,000 units depot penicillin in single injections are then given on alternate days for a period of 3 weeks. Mayer and Herkenhoff (1951) treating ten infants aged 4 days to 6 months, most of them with severe manifestations, had no untoward complications with a schedule of 3-hourly injections of 500 units penicillin for 2 days, increasing the dose gradually every 2 days up to 25,000 units at 3-hourly periods. Debré and others (1951) suggested 1-2 units per $\mathrm{kg}$. bodyweight for the first 3 days as a form of desensitization before beginning higher dosage.

Oral administration of penicillin has been acclaimed as singularly free of untoward accidents if given to infants under 6 months of age with congenital syphilis at a dosage of 100,000 units per $\mathrm{kg}$. bodyweight per day for a fortnight or longer (Weller, 1953; Scherzer, 1953).

Sudden death has not infrequently occurred in untreated infants with early and severe manifestations and their susceptibility to intercurrent infections is well known. Nevertheless, the trend of the disease in the cases reported leaves little doubt as to the ominous part the Jarisch-Herxheimer reaction played in the course of their illnesses.

\section{Summary}

(1) A Jarisch-Herxheimer reaction to penicillin was regarded as a contributory cause of death in ten cases of florid early congenital syphilis.

(2) Age and severe involvement of parenchymatous organs, particularly of the liver, seem to be predisposing factors.

(3) Methods of prevention are discussed.

I am greatly indebted to the Members of the Consultant Medical Staff of the three Manchester Children's Hospitals for permission to include cases in this study under their care and for granting access to their respective records. My thanks are also due to Dr. B. Marsden and Dr. F. Duran-Jorda for the post-mortem findings and, in particular, to Prof. W. F. Gaisford for his helpful criticism.

\section{REFERENCES}

Debré, R., Lamy, M., Mozziconacci, P, and Labesse, J. (1951). Sem. Hôp. Paris, 27, 1321.

Ehrengut, W. (1950), Arch. Kinderheilk., 140, 123.

Farmer, T. W. (1948). J. Amer. med. Ass., 138, 480.

Heyman, A., and Yampolsky, J. (1946). Amer. J. dis. Child., 71, 506. Sheldon, W. H., and Evans, L. D. (1952). British Journal of
Venereal Diseases, 28, 50.

Küster, F., and Bechmann, E. (1952). Kinderärztl. Prax., 20, 149. Mayer, J. B., and Herkenhoff, H. F. (1951). Ann. paediat. (Basel), 177,194

Morton, R. S. (1954). Brit. med. J., 1, 1470.

Oehme, J. (1951). Mschr. Kinderheilk., 99, 290 or 348.

Pardo, O. A., and Tucker, H. A. (1949). Amer. J. Syph., 33, 225.

Platou, R. V. (1949). Advanc. Pediat. 4, 39.

Putkonen, T. (1950). Dermatologica (Basel), 101, 313.

Scherzer, E. (1953). Mschr. Kinderheilk., 101, 268

Scott, V., Maxwell, R. W., and Skinner, J. S. (1949). J. Amer. med. Ass., 139, 217.

Seelemann, K., and Kornatz-Stegmann, B. (1952). Mschr.Kinderheilk., 100, 472 .

Seelig, L., and Sudhoff, K. E. (1952). Dtsch. med. Wschr., 77, 337. Stenger, K. (1950). Mschr. Kinderheilk., 98, 369.

Weller, R. (1953). Ibid., 101, 266. 